\title{
Development of an Experimental Apparatus for Investigating Lymphatic Pumping Activity of Murine Mesentery In Vivo
}

\author{
Nobuyuki ONO, Risuke MIZUNO*, Hiroshi NOJIRI*, and Toshio OHHASHI* \\ Department of Electronics and Control Engineering, Nagano National College of Technology, \\ Nagano, 381-8550 Japan; and \\ *The 1st Department of Physiology, Shinshu University School of Medicine, \\ Matsumoto, 390-8621 Japan
}

\begin{abstract}
The present study has been attempted to establish a modified intravital microscope system for investigating murine lymphatic pumping activity in vivo and evaluate whether or not there is rhythmic pumping activity of murine mesenteric lymphatic vessels in vivo. We designed and constructed a custom organ chamber with a semicircular channel $(8 \mathrm{~mm}$ in radius, $5 \mathrm{~mm}$ in width, $3 \mathrm{~mm}$ in depth), being suitable for the superfusing of murine mesentery in vivo. A marked lymphatic pumping activity was observed in the mesenteries of DDY mice. The maximal and minimal diameter and frequency in the
\end{abstract}

pumping activity were $60.9 \pm 1.0 \mu \mathrm{m}, 53.7 \pm$ $1.8 \mu \mathrm{m}$ and $12.8 \mathrm{~min}^{-1}(n=5)$, respectively. Both NE (norepinephrine, $10^{-8}-10^{-6} \mathrm{M}$ ) and TEA (tetraethylammonium, 1-10 mM) caused dosedependent constriction of the mesenteric lymphatic vessels in the mice. These findings suggest that a modified intravital microscope system with a specially designed and constructed edgemonitoring device enables us to investigate in vivo lymphatic circulation in murine mesenteries. [Japanese Journal of Physiology, 50, 25-31, 2000]

Key words: modified mesenteric chamber for mice, lymphatic pumping activity, murine mesentery, in vivo experiments, norepinephrine, TEA.

The lymphatic system plays an important role in regulating the transport of excess extracellular fluid and macromolecular substances, albumin and immunoglobulin, in tissues and organs. The lymphatic system also plays a key role in the absorption of fluid and fat from the lumen of the small intestine. The central lacteals begin in the intestinal villi. These lacteals converge to form submucosal lymphatic-collecting vessels which emerge from the mesenteric border as mesenteric lymphatics.

The transport of lymph depends on passive and active driving forces as well as on the rate of lymph production in organs and tissues [1]. The active driving mechanism may play a significant role in the centripetal propulsion of lymph, which is due to the intrinsic contractility of the lymphatic vessels [1-3]. There are marked species differences in existence of the intrinsic contractions and corresponding rhythmic pumping activity in vivo; sheep, cow, cat, guinea-pig and rat mesenteric lymphatic vessels demonstrate the contraction in vitro and the pumping activity in vivo $[1,2,4-9]$. No report, however, shows the rhythmic contraction in vitro and the pumping activity in murine mesenteric lymphatics in vivo.

Recently, development of molecular bioengineering enables us to utilize transgenic and knock-out mice, which have been used to understand the mechanisms of cardiovascular disease as well as physiological functions [10-14]. The mouse is one of the best species to establish gene-mutant animals. A specialized vital microscope system, however, has not been developed to study the mesenteric micro- and lymphcirculation in transgenic and wild mice.

Therefore, the present study was undertaken to es-

Received on August 2, 1999; accepted on November 4, 1999

Correspondence should be addressed to: Toshio Ohhashi, The 1st Department of Physiology, Shinshu University School of Medicine, 3-1-1 Asahi, Matsumoto, 390-8621 Japan. Tel: +81-263-37-2595, Fax: +81-263-36-5149, E-mail: ohhashi@sch.md.shinshu-u.ac.jp 

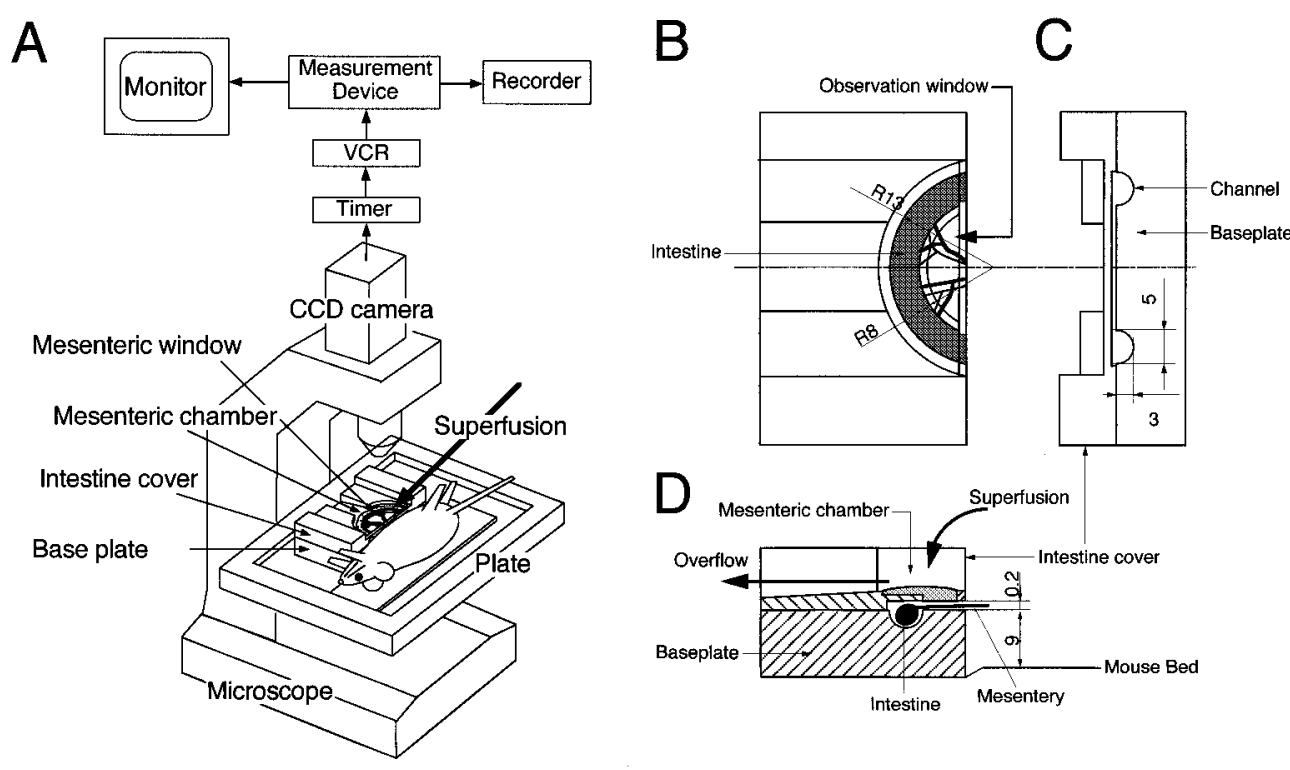

Fig. 1. An experimental layout of the modified intravital microscope system (A) and a custommade mesenteric chamber suitable for superfusion of murine mesentery in vivo ( $B, C$ and $D)$. $B, C$ and $D$ show top, front and sectional views of the chamber, respectively. Heated water $\left(37^{\circ} \mathrm{C}\right)$ was circulated at the bottom of the baseplate. tablish an intravital microscope system for investigating mesenteric lymphatic circulation and then evaluate whether or not rhythmic pumping activity exists, similar to rat, in murine mesenteric lymphatic vessels in vivo.

\section{MATERIALS AND METHODS}

Animals. Male DDY mice (5 to 6 weeks old, $28.8 \pm 1.0 \mathrm{~g}, n=5$ ) were used for the present studies. The mice were housed in an environmentally controlled vivarium and fed a standard pellet diet and water ad libitum. Access to food but not water was discontinued $18-20 \mathrm{~h}$ before experimental use. All experimental protocols were approved by the Animal Ethics Committee, Shinshu University School of Medicine, in accordance with the principles and guidelines of the Council of the American Physiological Society.

Surgical procedure. The mice were anesthetized by intraperitoneal injection of a mixture of $2 \% \alpha$-chloralose and $10 \%$ urethane $(0.7 \mathrm{ml} / 100 \mathrm{~g}$ b.w.). Additional anesthetic was supplemented ( $0.1 \mathrm{ml}$, I.M.) when the mice produced body movement, hyperventilation or increment of arterial blood pressure. Each mouse was tracheotomized and polyethylene tubing (SP102, Natsume, Japan) was inserted to ensure spontaneous respiration with room air. To measure the arterial blood pressure, the right carotid artery was cannulated by an elongated polyethylene tube (SP45, Natsume) connected to a pressure transducer (PD104, Toyoda, Japan). Changes in arterial blood pressure were recorded on a direct-writing recorder (Recti-Horitz 8K, Sanei-Sokki, Japan). The left femoral vein was also cannulated for intravenous infusion of $0.9 \%$ physiological saline $(0.1 \mathrm{ml} / \mathrm{h})$ with a syringe pump (STC-525, Terumo, Japan).

Figure 1 shows an experimental layout of the modified intravital microscope system (A) and a custommade mesenteric chamber suitable for superfusion of murine mesentery in vivo ( $\mathrm{B}, \mathrm{C}$ and $\mathrm{D})$. The mice were placed on a heated plate to keep the rectum temperature at $37-38^{\circ} \mathrm{C}$ throughout the experiments (Fig. 1A). After a midline incision of the abdomen was made, the mesentery adjacent to a segment of small intestine was exteriorized on the baseplate of the mesentery chamber (Fig. 1B, C and D). The exteriorized small intestine was positioned in a semicircular channel $(8 \mathrm{~mm}$ in radius, $5 \mathrm{~mm}$ in width, $3 \mathrm{~mm}$ in depth, Fig. 1C) on the baseplate of the chamber, and the mesentery was spread over an observation window in the chamber (Fig. 1B). The space between the intestine and semicircular channel was filled with physiological saline-soaked cotton strips. Care was taken not to twist or occlude the mesenteric lymphatic vessels as well as blood vessels. The exposed small intestine was covered with a layer of cotton and high vacuum silicone grease (Dow Corning, Japan). A plastic plate (intestine cover) was placed over the semi-circular channel in a manner that produced a seal between the intestine and the mesentery but did not obstruct blood and lymph flow. The mesenteric chamber was superfused with $37^{\circ} \mathrm{C}$ Krebs-bicarbonate solution (in $\mathrm{mM}): \mathrm{NaCl} 120, \mathrm{KCl} 5.9, \mathrm{NaHCO}_{3} 25.0, \mathrm{NaH}_{2} \mathrm{PO}_{4}$ $1.2, \mathrm{CaCl}_{2} 2.5, \mathrm{MgCl}_{2} 1.2$, and glucose 5.5 , which was aerated with a gas mixture of $5 \% \mathrm{CO}_{2}-95 \% \mathrm{~N}_{2}$ to keep a $\mathrm{pH}$ of 7.4. The rate of superfusion was kept at $6 \mathrm{ml} / \mathrm{min}$ during the experiments.

Analysis of murine lymphatic pumping activity. The custom-made murine mesenteric cham- 


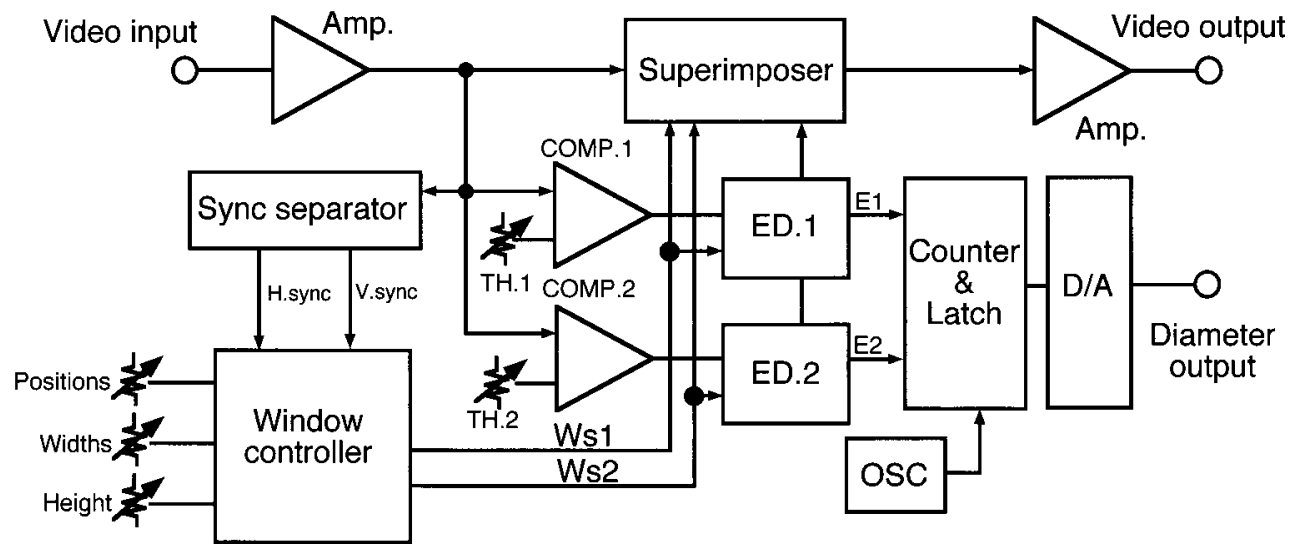

Fig. 2. A block diagram of the electrical circuit in the edge-monitoring device. Video input: video signal obtained by the CCD camera; COMP. 1 and COMP. 2: analog comparators; ED. 1 and ED. 2: edge detectors.

ber was transferred to the stage of an intravital microscope (BH-2, Olympus, Japan) (Fig. 1A). To measure the lymphatic pumping activity in murine mesentery, we selected a lymphatic vessel clearly identified from the adipose and surrounding tissues. The mesenteric lymphatics chosen for the observation were located 2 to $5 \mathrm{~mm}$ from the intestinal wall. Experiments were terminated if the mean arterial blood pressure fell below $80 \mathrm{mmHg}$. The image of lymphatic vessel was obtained through a $\times 4$ water-immersion objective lens with a numerical aperture of 0.1 (Nikon, Japan), a photoeyepiece lens $(\times 5)$, and a monochrome CCD camera (KP-M1, Hitachi, Japan), and then the image was recorded on a video cassette recorder (BR-S800, Victor, Japan).

Description of the edge-monitoring device for measuring intraluminal diameter of the lymphatic vessel. In this study, we designed a new edge-monitoring device to measure changes in the intraluminal diameter of lymphatic vessels. The image of a lymphatic vessel obtained using the CCD camera was displayed on a monochrome TV monitor (PVM1454Q, Sony, Japan) via the device. The intraluminal diameter of the lymphatic vessel was calculated by an edge-detection method $[15,16]$.

Figure 2 shows a block diagram of the electrical circuit in the edge-monitoring device. The video signals obtained by the CCD camera were used as an input signal of the device (Fig. 2, video input). The device also had two edge-detection circuits which consisted of an analog comparator (Fig. 2, COMP. 1 and 2) and an edge detector (Fig. 2, ED. 1 and 2). The changes in the diameter of the lymphatic vessels were measured automatically using the electrical circuit. Figure $3 \mathrm{~A}$ shows a representative picture on the TV monitor equipped with two superimposed windows. Figure 3B also demonstrates a schematic diagram of electrical processing to measure the intraluminal diameter of the lymphatic vessel. Firstly, two electrical

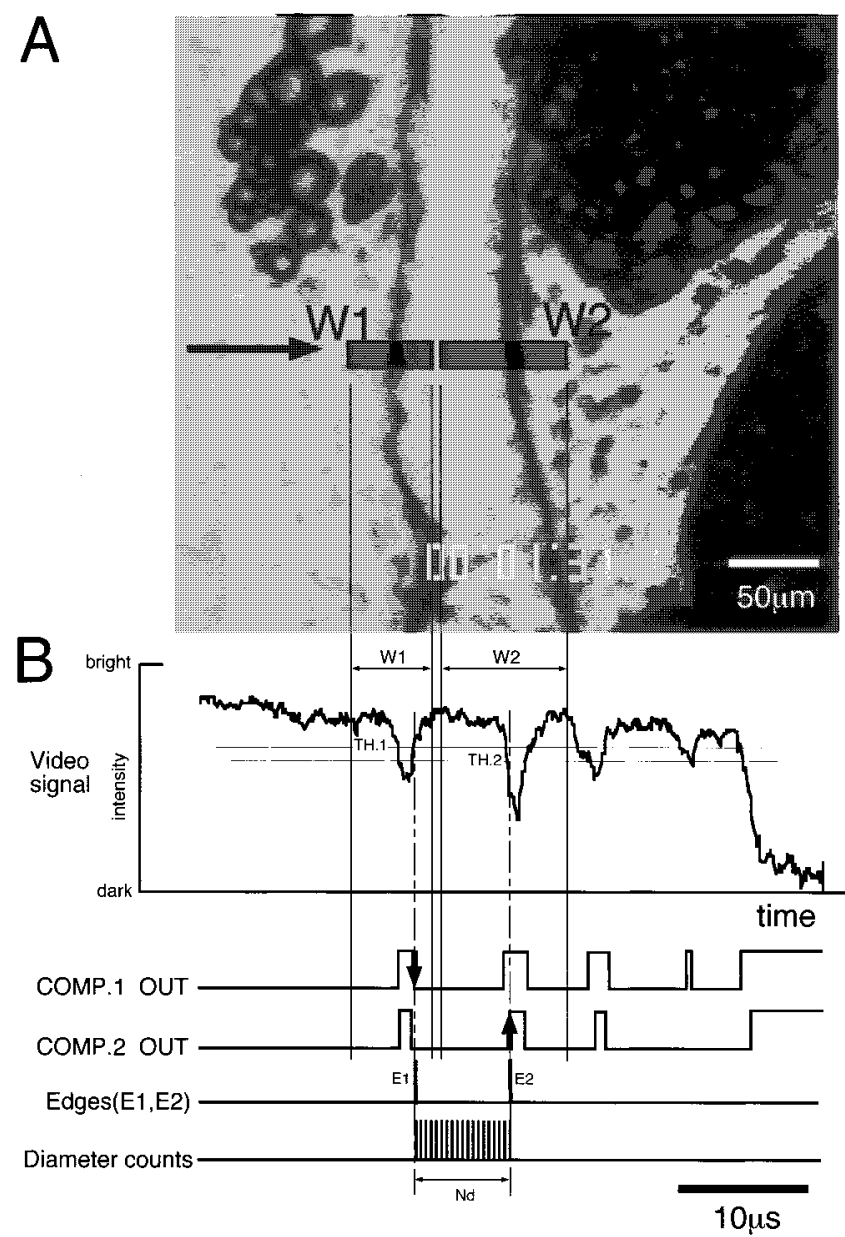

Fig. 3. A: Representative picture of the murine mesentery on the TV monitor equipped with two superimposed windows (W1 and W2). B: Schematic diagram of electrical processing to measure the intraluminal diameter of murine mesenteric lymphatic vessels. $\mathrm{TH} .1$ and TH. 2: threshold voltages; E1 and E2: outputs of edge detectors; $N_{d}$ : number of electrical pulses corresponding to the intraluminal diameter.

windows were adjusted manually on both sides of the lymphatic wall displayed on the TV monitor. The changes in the optical density on a horizontal line at 


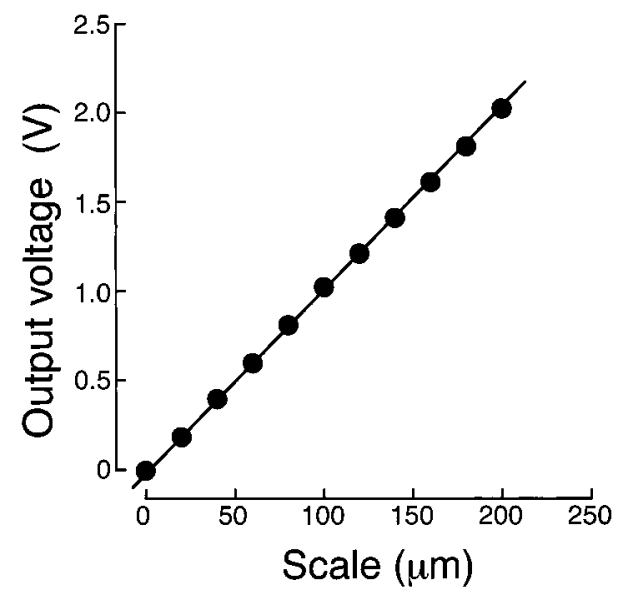

Fig. 4. A regression analysis of the relationship between the output voltage of the device $(V$ and scale of an objective micrometer $(\boldsymbol{\mu m})$. The regression line: scale $=100 \times V(r=1.00, p<0.001)$.

the top of the windows (Fig. 3A, arrow) were used to detect both edges of the image of the lymphatic vessel. To keep correct detection, the longitudinal axis of the lymphatic vessel was adjusted perpendicularly against the horizontal line by rotating the CCD camera. The video signals (Fig. 3B, W1 and W2) at the horizontal line were compared independently with the corresponding threshold voltages using the analog comparators. The outputs of comparator 1 and 2 (Fig. 3B, COMP. 1 and 2) were used to decide, electrically, both edges of the lymphatic wall. The total number counted by edge detectors (Fig. 3B, Nd) was converted into an output of analog voltage through a $\mathrm{D} / \mathrm{A}$ converter and then recorded as the intraluminal diameter of the lymphatic vessel on a direct-writing recorder. Figure 4 demonstrates a calibration curve which shows a linear relationship between the output voltage of the device $(V)$ and the scale of an objective micrometer ( $\mu \mathrm{m}$, Olympus). The relationship is that the scale $(\mu \mathrm{m})$ equals 100 times $V(\mathrm{~V})$. According to this relationship, the theoretical resolution power of the diameter measurement in this device was $0.38 \mu \mathrm{m}$ because electrical resolution of the $\mathrm{D} / \mathrm{A}$ converter corresponding to one pulse width in the $N_{\mathrm{d}}$ (Fig. 3B) is $3.8 \mathrm{mV}$.

Measurement of lymphatic pumping parameters. After equilibration for $20 \mathrm{~min}$, the maximum diameter $\left(D_{\max }, \mu \mathrm{m}\right)$, minimum diameter $\left(D_{\min }\right.$, $\mu \mathrm{m})$ and contraction frequency $\left(\mathrm{min}^{-1}\right)$ were measured for $10 \mathrm{~min}$ as control parameters of lymphatic pumping activity in the DDY mice. After another equilibration for $20 \mathrm{~min}$, norepinephrine (NE, $10^{-8}$ to $10^{-6} \mathrm{M}$ ) or tetraethylammonium (TEA, 1, 5 and $10 \mathrm{mM}$ ) was added to the superfusing solution bathing all mesenteries of the mice for $5 \mathrm{~min}$. The parameters
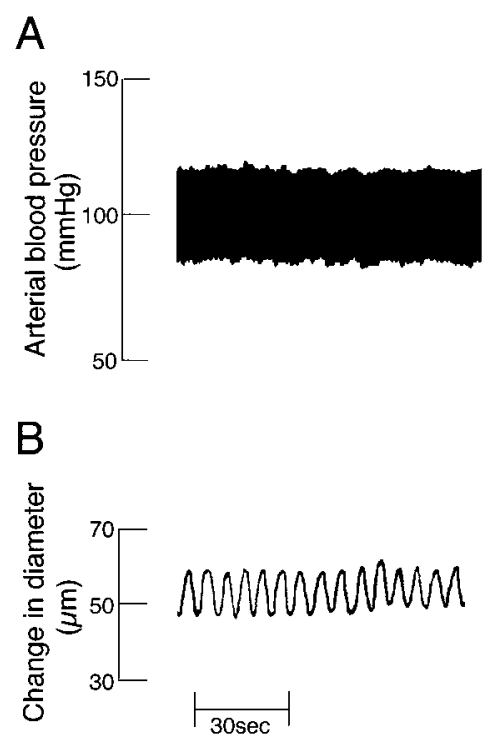

Fig. 5. Representative tracings of changes in arterial blood pressure (A) and the diameter of the mesenteric lymphatic vessel (B) in a DDY mouse.

of lymphatic pumping activity in vivo were also measured in the same manner as those in each control. The other parameters of the lymphatic pumping activity, stroke volume index and ejection fraction, were calculated as follows: stroke volume index $=\pi\left(D_{\max } / 2\right)^{2}-$ $\pi\left(D_{\min } / 2\right)^{2}$, ejection fraction $=\left\{\pi\left(D_{\max } / 2\right)^{2}-\pi\left(D_{\min } / 2\right)^{2}\right\} /$ $\pi\left(D_{\max } / 2\right)^{2}[4]$.

Drugs. All salts (Wako, Japan), NE hydrochloride and TEA bromide (Sigma, St. Louis, USA) were used in the present study. Concentrations of the drugs were expressed as a final concentration in the mesenteric chamber. All salts and drugs were prepared on the day of the experiment.

Data analysis. Experimental values in the text, figures and tables are expressed as mean \pm standard error of the mean. The $n$ indicates the number of experimental animals examined in the present study.

\section{RESULTS}

The mean arterial pressure and heart rate of the DDY mice were $103 \pm 3 \mathrm{mmHg}$ and $444 \pm 17$ beats $/ \mathrm{min}$, respectively.

\section{Lymphatic pumping activity in the mesenteric lymphatic vessels of DDY mice}

Figure 5 shows representative tracings of changes in the arterial pressure (A) and diameter of mesenteric lymphatic vessel (B) in a DDY mouse. The vessel demonstrated clearly rhythmic beatings. Thus, the $D_{\max }, D_{\min }$ and contraction frequency in the lymphatic pumping activity were $60 \mu \mathrm{m}, 48 \mu \mathrm{m}$ and $12 \mathrm{~min}^{-1}$, 
respectively. The averages of the $D_{\max }, D_{\min }$ and frequency in the mice were $60.9 \pm 1.0 \mu \mathrm{m}, 53.7 \pm 1.8 \mu \mathrm{m}$ and $12.8 \mathrm{~min}^{-1}(n=5)$, respectively. The stroke volume index and ejection fraction of the lymphatic pumping activity were calculated to be $641 \pm 113 \mu \mathrm{m}^{2}$ $(n=5)$ and $0.22 \pm 0.04(n=5)$, respectively.

\section{Effects of NE and TEA on changes in the di- ameters of mesenteric lymphatic vessels in DDY mice}

Figure 6 demonstrates representative tracings of the effects of $10^{-6} \mathrm{M}$ NE (A) and $5 \mathrm{mM}$ TEA (B) on the diameters of mesenteric lymphatic vessels in DDY mice. Both $10^{-6} \mathrm{M} \mathrm{NE}$ and $5 \mathrm{mM}$ TEA caused a marked constriction of the lymphatic vessels superimposed with oscillatory changes of diameter in the mice. Thus, in response to the $10^{-6} \mathrm{M} \mathrm{NE}$, the diameter of the lymph vessels in the mice was reduced from 53 to $38 \mu \mathrm{m}$ (Fig. 6A). The NE-induced maximal responses of the lymph vessels are summarized in Fig. 7A. TEA $(5 \mathrm{mM})$ also caused a shortening of the diameter, from 51 to $39 \mu \mathrm{m}$, in the lymph vessels of the mice (Fig. 6B). Such data are summarized in Fig. 7B.

\section{DISCUSSION}

The major findings of the present study are: (1) a modified intravital microscope system enables us to study lymphatic circulation of murine mesenteries in vivo; (2) mesenteric lymphatic vessels in DDY mice exhibit rhythmic pumping activity in vivo; and (3) NE and TEA caused a significant constriction of the lymphatic vessels in the murine mesenteries.

\section{A modified intravital microscope system} for murine mesentery. To investigate the lymphatic pumping activity of murine mesenteries in vivo, major modifications of a classical intravital microscope system are summarized as follows: (1) improvement in the size and shape of the superfusion chamber for fitting murine mesenteries, and (2) construction of a cheaper and more concise edge-monitoring device, compared to the edge detection software systems on the market, which enables us to continuously measure changes in the diameter of the lymphatic vessels. The size and shape of the mesenteric chamber were constructed to provide the highest probability of success and to be suitable for the investigation of murine lymphatic pumping activity in vivo. Additionally, we have taken care in deciding the height of the chamber between the heated plate and the observation window, which has played a crucial role in preventing leakage of the superfused solution into the abdomen cavity.

A concise edge-monitoring device was also de-

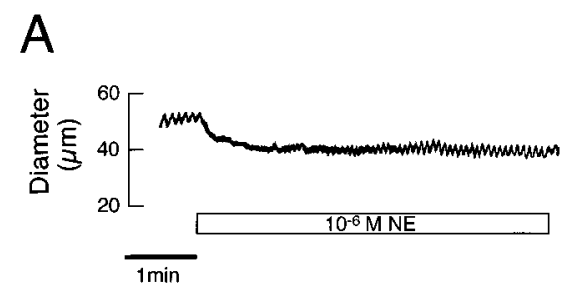

\section{B}

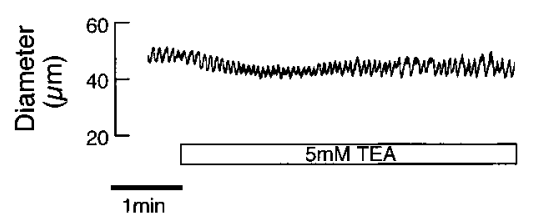

Fig. 6. Representative tracings of the effects of $10^{-6} \mathrm{M}$ norepinephrine (NE, A) and $5 \mathrm{mM}$ tetraethylammonium (TEA, B) on the diameters of mesenteric lymphatic vessels in DDY mice.
A

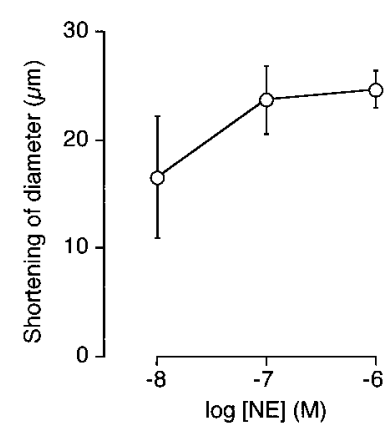

B

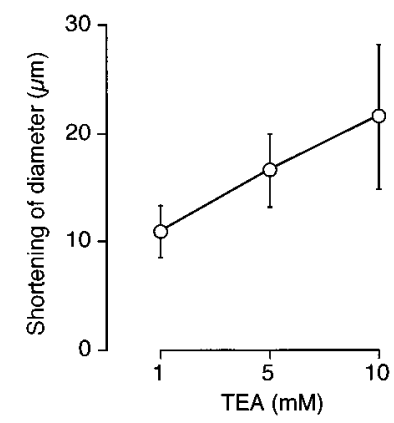

Fig. 7. Dose-maximal constrictor response curves for NE (A) or TEA (B) in the mesenteric lymphatic vessels of DDY mice.

signed in the present study to measure continuous changes in the diameter of murine mesenteric lymphatic vessels in vivo using the technique with a binary image [17]. The techniques for recording of vascular diameters that have been widely used are as follows: image-splitting method using a mechanical splitter [18] or an electrical splitter [15, 16, 19], and a computerized image-processing method utilized with changes in the intensity of video signals [20-22]. Both of the methods were, however, difficult for recording real-time changes in the diameter in vivo. These methods also required complicated electrical and mechanical circuits. In addition, there is the other problem of deciding the real border between intraluminal space and the wall of the blood vessel. The blood flow in microcirculation consists of red blood cell columns in the intraluminal space, which causes a complex intensity profile of video signals corresponding to the real border between the space and wall. 
Thus, it is difficult to detect the intraluminal edges of video signals clearly and automatically. The lymphatic vessels have, however, no blood cell columns, and then the edges of the lymphatic walls were able to easily detect the video signals as shown in Fig. 3.

On the other hand, there are a number of edge-detection software systems on the market which seem to do a very good job of following vessel diameters. Considering the situation, we designed and constructed a cheaper and more concise edge-monitoring device for continuously recording the diameter of murine mesenteric lymphatic vessels. The characteristics of the device are summarized as follows. (1) The electrical circuits were made very concisely with low cost. (2) Operation of the device is very easy because both the binary and original images are simultaneously displayed on the TV monitor. (3) The device is also able to detect real-time changes in the diameter of vascular vessels because the frequency characteristic of the device is kept at $60 \mathrm{~Hz}$.

Existence of rhythmic pumping activity of mesenteric lymphatics in DDY mice. Several in vivo studies demonstrate that spontaneous oscillatory changes in the diameters of mesenteric lymphatic vessels are present in cats [7], guinea-pigs [4, 5, 23, 24] and rats [4, 25, 26]. There is, however, no information regarding the existence of rhythmic pumping activity in murine mesenteric lymphatic vessels in vivo. The present study is the first to demonstrate that a marked rhythmic pumping activity exists in vivo in the mesenteric lymphatic vessels of DDY mice. There are two studies that investigated lymphatic circulation in vivo in murine tails $[27,28]$. Such rhythmic beatings in the murine tails, however, have not been confirmed. The maximum and minimum diameters of the lymphatic vessels corresponding to the rhythmic beatings were $60.9 \pm 1.0$ and $53.7 \pm 1.8 \mu \mathrm{m}$, respectively. The frequency in the murine mesenteric pumping activity was $12.8 \pm 0.7 \mathrm{~min}^{-1}$, being higher compared with other rodents $[5,25,26]$. In contrast, the ejection fraction $(0.22 \pm 0.04)$ and stroke volume index $(641 \pm$ $\left.113 \mu \mathrm{m}^{2}\right)$ in the murine mesenteric lymphatic vessels were smaller than those obtained with rats $(0.65 \pm 0.00$ and 3,700 $\pm 480 \mu \mathrm{m}^{2}$ ) [26].

NE and TEA-induced constrictor responses of the lymphatic vessels in DDY mice. Both

NE and TEA caused a dose-dependent constriction of the mesenteric lymphatic vessels in the mice (Fig. 6). These drugs also produced spontaneous oscillations of the diameters, which were superimposed on the druginduced shortening of the diameters of the lymphatic vessels in the mice (Fig. 6).

It is well-known that humoral and neural factors af- fect the mechanical activity of the smooth muscles in collecting mesenteric lymphatics [29]. The rhythmic spontaneous activity of the mesenteric lymphatics in rats and cows depends on an extracellular $\mathrm{Ca}^{2+}$ and a voltage-dependent $\mathrm{L}$-type $\mathrm{Ca}^{2+}$ channel $[9,30]$. Recently, some investigators have also reported that $\mathrm{K}^{+}$ channels regulate the membrane potential of lymphatic smooth muscles in sheep and guinea-pig mesenteric lymphatics [23, 31]. We also demonstrated that ATP-sensitive $\mathrm{K}^{+}$channels are involved in the regulation of spontaneous activity in lymphatic smooth muscles in isolated rat mesenteric lymphatic vessels [32]. Considering these findings for the lymphatic smooth muscles, TEA, a non-selective $\mathrm{K}^{+}$ channel blocker, seemed to reduce all kinds of $\mathrm{K}^{+}$ channels of the lymphatic smooth muscles, totally depolarize the membrane potential, activate the depolarization-mediated $\mathrm{Ca}^{2+}$ permeability and $\mathrm{Ca}^{2+}$-release from the plasma membrane, and then result in a marked constriction of the lymphatic smooth muscles. The hypothesis may be, in part, related to the evidence that ouabain-induced inhibition of the electrogenic sodium pump of the lymphatic smooth muscles in bovine mesenteric lymphatic vessels has produced a marked vasoconstriction [33].

The authors are grateful to Dr. Fumitaka Ikomi, The 1st Department of Physiology, Shinshu University School of Medicine, for his technical support. This study was supported in part by Grants-in-Aid for Scientific Research (08457009) from Japanese Ministry of Education, Science, Sports, and Culture.

\section{REFERENCES}

1. Ohhashi T, Azuma T, and Sakaguchi M: Active and passive mechanical characteristics of bovine mesenteric lymphatics. Am J Physiol 239 (Heart Circ Physiol 8): H88-H95, 1980

2. Mawhinney HJD and Roddie IC: Spontaneous activity in isolated bovine mesenteric lymphatics. J Physiol (Lond) 229: 339-348, 1973

3. McHale NG and Roddie IC: The effect of transmural pressure on pumping activity in isolated bovine lymphatic vessels. J Physiol (Lond) 261: 255-261, 1976

4. Benoit JN, Zawieja DC, Goodman AH, and Granger $\mathrm{HJ}$ : Characterization of intact mesenteric lymphatic pump and its responsiveness to acute edemagenic stress. Am J Physiol 257 (Heart Circ Physiol 26): H2059-H2069, 1989

5. Hargens AR and Zweifach BW: Contractile stimuli in collecting lymph vessels. Am J Physiol 233 (Heart Circ Physiol 2): H57-H65, 1977

6. Van Helden DF: Pacemaker potentials in lymphatic smooth muscle of the guinea-pig mesentery. J Physiol (Lond) 471: 465-479, 1993

7. Zweifach BW and Prather JW: Micromanipulation of 
pressure in terminal lymphatics in the mesentery. Am $\mathrm{J}$ Physiol 228: 1326-1335, 1975

8. Hollywood MA and McHale NG: Mediation of excitatory neurotransmission by the release of ATP and noradrenaline in sheep mesenteric lymphatic vessels. J Physiol (Lond) 481: 415-423, 1994

9. Mizuno R, Dörnyei G, Koller A, and Kaley G: Myogenic responses of isolated lymphatics: modulation by endothelium. Microcirculation 4: 413-420, 1997

10. Huang PL, Huang Z, Mashimo H, Bloch KD, Moskowitz MA, Bevan JA, and Fishman MC: Hypertension in mice lacking the gene for endothelial nitric oxide synthase. Nature 377: 239-242, 1995

11. Jeltsch $M$, Kaipainen A, Joukov V, Meng X, Lakso M, Rauvala H, Swartz M, Fukumura D, Jain RK, and Alitalo $\mathrm{K}$ : Hyperplasia of lymphatic vessels in VEGF-C transgenic mice. Science 276: 1423-1425, 1997

12. Ku DD, Guo L, Dai J, Acuff CG, and Steinhelper ME: Coronary vascular and endothelial reactivity changes in transgenic mice overexpressing atrial natriuretic factor. Am J Physiol 271 (Heart Circ Physiol 40): H2368-H2376, 1996

13. Kurihara $Y$, Kurihara $H$, Suzuki $H$, Kodama T, Maemura K, Nagai R, Oda H, Kuwaki T, Cao WH, Kamada N, Jishage K, Ouchi Y, Azuma S, Toyoda Y, Ishikawa T, Kumada M, and Yazaki Y: Elevated blood pressure and craniofacial abnormalities in mice deficient in endothelin-1. Nature 368: 703-710, 1994

14. Steudel W, Ichinose F, Huang PL, Hurford WE, Jones RC, Bevan JA, Fishman MC, and Zapol WM: Pulmonary vasoconstriction and hypertension in mice with targeted disruption of the endothelial nitric oxide synthase (NOS 3) gene. Circ Res 81: 34-41, 1997

15. Johnson PC: Measurement of microvascular dimensions in vivo. J Appl Physiol 23: 593-596, 1967

16. Johnson PC: Photometric scanning techniques for measurement of blood vessel dimensions. Microvasc Res 5: 292-298, 1973

17. Sakaguchi M, Ohhashi T, and Azuma T: A camera-type diameter gauge applicable to small blood and lymph vessels. Pflügers Arch 388: 261-265, 1980

18. Baez S: Recording of microvascular dimensions with an image-splitter television microscope. J Appl Physiol 21: 299-301, 1966

19. Kaufman $A G$ and Intaglietta M: Automated diameter measurement of vasomotion by cross-correlation. Int $\mathrm{J}$ Microcirc Clin Exp 4: 45-53, 1985

20. Beresford-Smith B, Nesbitt KV, and Van Helden DF: Edge detection at multiple locations using a 'radar' tracking algorithm as exemplified in isolated guinea- pig lymphatic vessels. J Neurosci Methods 49: 69-79, 1993

21. Neild TO: Measurement of arteriole diameter changes by analysis of television images. Blood Vessels 26: 48-52, 1989

22. Minamiyama M and Hanai S: Propagation properties of vasomotion at terminal arterioles and precapillaries in the rabbit mesentery. Biorheology 28: 275-286, 1991

23. Von der Weid PY and Van Helden DF: $\beta$-Adrenoceptormediated hyperpolarization in lymphatic smooth muscle of guinea pig mesentery. Am J Physiol 270 (Heart Circ Physiol 39): H1687-H1695, 1996

24. Crowe MJ, von der Weid PY, Brock JA, and Van Helden DF: Co-ordination of contractile activity in guinea-pig mesenteric lymphatics. J Physiol (Lond) 500: 235-244, 1997

25. Zawieja DC, Davis KL, Schuster R, Hinds WM, and Granger HJ: Distribution, propagation, and coordination of contractile activity in lymphatics. Am J Physiol 264 (Heart Circ Physiol 33): H1283-H1291, 1993

26. Zhang JL, Yokoyama S, and Ohhashi T: Inhibitory effects of fluorescein isothiocyanate photoactivation on lymphatic pump activity. Microvasc Res 54: 99-107, 1997

27. Berk DA, Swartz MA, Leu AJ, and Jain RK: Transport in lymphatic capillaries. II. Microscopic velocity measurement with fluorescence photobleaching. Am J Physiol 270 (Heart Circ Physiol 39): H330-H337, 1996

28. Swartz MA, Berk DA, and Jain RK: Transport in lymphatic capillaries. I. Macroscopic measurements using residence time distribution theory. Am J Physiol 270 (Heart Circ Physiol 39): H324-H329, 1996

29. Ohhashi $\mathrm{T}$ : Mechanisms for regulating tone in lymphatic vessels. Biochem Pharmacol 45: 1941-1946, 1993

30. Azuma T, Ohhashi T, and Roddie IC: Bradykinin-induced contractions of bovine mesenteric lymphatics. J Physiol (Lond) 342: 217-227, 1983

31. Cotton KD, Hollywood MA, McHale NG, and Thornbury KD: Outward currents in smooth muscle cells isolated from sheep mesenteric lymphatics. J Physiol (Lond) 503: 1-11, 1997

32. Mizuno R, Ono N, and Ohhashi T: Involvement of ATPsensitive $\mathrm{K}^{+}$channels in spontaneous activity of isolated lymph microvessels. Am J Physiol 277 (Heart Circ Physiol): H1453-H1456, 1999

33. Ohhashi T and Azuma T: Effect of potassium on membrane potential and tension development in bovine mesenteric lymphatics. Microvasc Res 23: 93-98, 1982 